\title{
Robot-Aided Learning and r-Learning Services
}

\author{
Jeonghye Han \\ Department of Computer Education \\ Cheongju National University of Education \\ Republic of Korea
}

\section{Introduction}

To date, there have been many studies that have deployed robots as learning and teaching assistants in educational settings to investigate their pedagogical effects on learning and teaching. Hendler (2000) categorized the robots with which learners may interact in the future into five categories, i.e., toy robotics, pet robotics, interactive displays, service robotics including assistive ones, and educational robotics. Goodrich and Schultz (2007) classified the educational service robots into assistive and educational robotics. The robots that can serve for educational purposes can be divided into two categories: educational robotics (also referred to as hands-on robotics), and educational service robotics. The difference between these two types of robotics stems from the primary user groups. Educational robotics has been used by prosumers, a blend of producers and consumers, while educational service robots show a clear boundary between the producers and consumers. In general, the latter takes anthropomorphized forms to substitute or support teachers. It can also add more than what computers have offered to aid language learning because their anthropomorphic figures lower the affective filter and provide Total Physical Response (TPR) in terms of actions, which may lead to form social interactions. This chapter focuses on educational service robots.

Taylor (1980) emphasized that computers have played important roles as educational tutors, tools and tutees. It seems that educational service robots can act as emotional tutors, tutoring assistants (teaching assistants), and peer tutors. The tutor or teaching assistant robots can also be a kind of assistant for innovative educational technologies for blended learning in order to obtain the knowledge and skills under the supervision and support of the teacher inside and outside the classroom. Examples of this include computers, mobile phones, Sky TV or IP TV channels and other electronics. The studies of Mishra and Koehler (2006) probed into teachers' knowledge, building on the idea of Pedagogical Content Knowledge (PCK) suggested by Shulman (1987). They extended PCK to consider the necessary relationship between technology and teachers' subject knowledge and pedagogy, and called this Technological Pedagogical Content Knowledge (TPCK), as shown in Fig. 3. An educational service robot as a teaching and learning assistant for blended learning is divided into three categories: the tele-operated (or tele-conference, tele-presence) type, autonomous type, and transforming type, according to the location of TPCK, as displayed in Table 1.

Source: Human-Robot Interaction, Book edited by: Daisuke Chugo,

ISBN 978-953-307-051-3, pp. 288, February 2010, INTECH, Croatia, downloaded from SCIYO.COM 


\begin{tabular}{|c|c|c|c|}
\hline Types of Robots & The location of TPCK & Applications & \multicolumn{1}{c|}{ Tele-operator } \\
\hline $\begin{array}{c}\text { tele-operated } \\
\text { (tele-presence, } \\
\text { tele-conferenc) }\end{array}$ & tele-operator's brain & $\begin{array}{c}\text { PEBBLES } \\
\text { SAKURA } \\
\text { Giraffe } \\
\text { Some Korean robots }\end{array}$ & $\begin{array}{c}\text { a child } \\
\text { native speakers } \\
\text { parents }\end{array}$ \\
\hline Autonomous & Robot's intelligence & Irobi, Papero, RUBI & \\
\hline $\begin{array}{l}\text { Transforming } \\
\text { (Convertible) }\end{array}$ & $\begin{array}{c}\text { tele-operator's brain } \\
\text { or robot's intelligence }\end{array}$ & iRobiQ \\
\hline
\end{tabular}

Table 1. Educational Service Robots for Blended Learning

Tele-operated robots in educational environments have substituted teachers in remote places, and have provided the tele-presence of educational services through instructors' remote control. The PEBBLES (Providing Education By Bringing Learning Environments to Students) of Telebotics Inc., which are remote-controlled mobile video conferencing platforms, enable a child due to illness or for other reasons, who is far away, to enjoy all the benefits of real-school life face to face (Williams et al., 1997). The Giraffe of HeadThere Inc. provides the service of babysitter supervision, and it can be used like PEBBLES. The physical version of the speech-driven embodied group-entrained communication system SAKURA with InterRobots and InterActor (Watanabe et al., 2003; 2007) is one of this kind of robot. Since 2008, some tele-operated robots have been commercialized to teach foreign languages to Korean children by English-speakers in the USA or Australia. Since the robots' anthropomorphic forms resemble the English-speakers, it may reduce the language learners' affective filter and strengthens the argument for a robot-based education that is remotely controlled by a native speaker. Furthermore, tele-operated robots, because of their anthropomorphic bodies, might fairly overcome the two outstanding issues of videoconferencing, eye contact and appearance consciousness. These issues are preventing videoconferencing from becoming the standard form of communication, according to Meggelen (2005).

With respect to the autonomous robots, the TPCK acts as the robots' intelligence. Hence, it can function as an instructor, instructor assistant, and peer tutor. Because robots have technological limitations in artificial intelligence, robot-based education should prefer focusing more on children's education. Although current autonomous robots narrowly have TCK, and not TPCK, many previous studies (Kanda et al., 2004; Han et al., 2005; Hyun et al., 2008; Movellan et al., 2009) have displayed positive results in using iRobiQ, Papero, RUBI in teaching children. This will be discussed further in the next chapter. Convertible robot can provide both tele-operation and autonomous control, and converts between the two depending on the surroundings or the command. These robots speak in TTS when they are in the autonomous mode, but in the voice of a remote instructor when it is in the tele-operated mode. The conversion between machine and natural voices might confuse children about the robot's identity. Therefore, the mode of transformation should be explicitly recognizable to children.

Robotic learning (r-Learning) is defined as learning by educational service robots, and has been identified as robot-aided learning (RAL), or robot assisted learning, in this study. The collection of educational interaction offered by educational service robots can be referred to 
as r-Learning Services (Han et al., 2009a; Han \& Kim, 2009; Han \& Kim, 2006). The purpose of this chapter was to describe the service framework for r-Learning, or RAL. This study begins by a review of literature on educational service robots to classify the r-Learning taxonomy. Then, this study demonstrates case studies for the adoption of r-Learning services in an elementary school. Also, this study discusses the results, focusing on how rLearning services teachers and students feel, and the possibility of commercialization of this technology. Finally, this study discusses future work in this field.

\section{Related works}

A growing body of work investigates the impact on RAL through educational service robots. In Table 2, the mains of existing studies are categorized into groups by the type of robot, the role of the robot, the target group, subjects taught, use of visual instruction material (such as Computer Aided Instruction, or CAI, and Web-based Instruction, or WBI), the type of educational service provided, and the number and duration of each field experiment.

\begin{tabular}{|c|c|c|c|c|c|c|c|c|c|c|}
\hline & & \begin{tabular}{|c|} 
Fels \\
\& Weiss \\
\end{tabular} & \begin{tabular}{|c|}
$\begin{array}{c}\text { Kanda } \\
\text { et al. }\end{array}$ \\
\end{tabular} & $\begin{array}{c}\text { Han } \\
\text { \& Kim } \\
\end{array}$ & $\begin{array}{c}\text { Watanabe } \\
\text { et al. }\end{array}$ & Osada & $\begin{array}{l}\text { Hyun } \\
\text { et al. }\end{array}$ & $\begin{array}{l}\text { You } \\
\text { et al. }\end{array}$ & $\begin{array}{c}\text { Movellan } \\
\text { et al. }\end{array}$ & YuJin \\
\hline \multirow{3}{*}{ Type } & Autonomous & & $\bullet$ & $\bullet$ & & $\bullet$ & $\bullet$ & & $\bullet$ & \\
\hline & Tele-operated & $\bullet$ & & & $\bullet$ & & & $\bullet$ & & \\
\hline & Transforming & & & & & & & & & $\bullet$ \\
\hline \multirow{3}{*}{ Role } & Tutor & & & & Avatar & & & & & \\
\hline & $\begin{array}{l}\text { Tutoring } \\
\text { Assistant }\end{array}$ & & & $\bullet$ & & & & $\bullet$ & & $\bullet$ \\
\hline & Peer Tutor & $\begin{array}{c}\text { Not tutor } \\
\text { (Peer) }\end{array}$ & $\bullet$ & & Avatar & $\bullet$ & $\bullet$ & & $\bullet$ & $\bullet$ \\
\hline \multirow{3}{*}{$\begin{array}{l}\text { Target } \\
\text { Group }\end{array}$} & Toddler & & & & $\bullet$ & $\bullet$ & $\bullet$ & & $\bullet$ & $\bullet$ \\
\hline & Children & $\bullet$ & $\bullet$ & $\bullet$ & $\bullet$ & & & $\bullet$ & & $\bullet$ \\
\hline & Silver & & & & & & & & & \\
\hline \multirow{3}{*}{ Subject } & English & & $\bullet$ & $\bullet$ & \multirow{3}{*}{$\begin{array}{c}\text { Any } \\
\text { Subject }\end{array}$} & & & $\bullet$ & & $\bullet$ \\
\hline & $\begin{array}{l}\text { Domestic } \\
\text { Language }\end{array}$ & & & $\bullet$ & & & $\bullet$ & & $\bullet$ & $\bullet$ \\
\hline & Etc & $\bullet$ & & $\bullet$ & & Nursing & & & & $\bullet$ \\
\hline \multirow{2}{*}{$\begin{array}{l}\text { Instruct- } \\
\text { ion }\end{array}$} & Visual & & & $\bullet$ & $\bullet$ & & $\bullet$ & & $\bullet$ & $\bullet$ \\
\hline & Not Visual & $\bullet$ & $\bullet$ & & & $\bullet$ & & $\bullet$ & & \\
\hline \multirow{5}{*}{ Services } & Conversation & $\bullet$ & $\bullet$ & $\bullet$ & $\bullet$ & $\bullet$ & $\bullet$ & $\bullet$ & $\bullet$ & $\bullet$ \\
\hline & Edutainment & & $\bullet$ & & $\bullet$ & $\bullet$ & $\bullet$ & & $\bullet$ & $\bullet$ \\
\hline & \begin{tabular}{|l|} 
Showing \\
Instruction
\end{tabular} & & & $\bullet$ & $\bullet$ & & $\bullet$ & & $\bullet$ & $\bullet$ \\
\hline & Calling User & & $\bullet$ & & $\bullet$ & $\bullet$ & & & $\bullet$ & $\bullet$ \\
\hline & VR or AR & & & AV & VR, AR & & & & & $\mathrm{AR}$ \\
\hline \multirow{2}{*}{$\begin{array}{c}\text { Experi- } \\
\text { ment }\end{array}$} & Term & $\begin{array}{c}6 \\
\text { weeks }\end{array}$ & $\begin{array}{c}2 \\
\text { weeks }\end{array}$ & $\begin{array}{c}40 \mathrm{mins} \\
\mathrm{X} 3\end{array}$ & 185 days & $\begin{array}{c}185 \\
\text { days }\end{array}$ & $\begin{array}{c}1 \\
\text { month }\end{array}$ & $\begin{array}{c}40 \mathrm{mins} \\
\mathrm{X} 2\end{array}$ & $\begin{array}{c}2 \\
\text { weeks }\end{array}$ & \multirow[t]{2}{*}{ N/A } \\
\hline & Effect & $\bullet$ & Motive & $\bullet$ & $\mathrm{N} / \mathrm{A}$ & $\mathrm{N} / \mathrm{A}$ & $\bullet$ & & $\bullet$ & \\
\hline
\end{tabular}

N/A: we did not obtain related information in detail

Table 2. Some Reviews of Literature on RAL

\section{Robot Types}

Most of the recent studies about the types of robots (e.g., Kanda et al., 2004; Han et al., 2005; Han \& Kim, 2006; You et al., 2006; Hyun et al., 2008; Movellan et al., 2009; Han et al. 2009a) 
have concentrated on the autonomous types of educational service robots. Tele-operated robots for educational purposes were shown in Williams et al. (1997), Fels and Weiss (2001), Watanabe et al. (2003), and You et al. (2006). The tele-operators of these studies were students or parents, not teachers or teaching assistants, except in You et al. (2006). iRobiQ, made by Yujin Robot Inc., has commercialized a transforming type that can act as both an autonomous and a tele-operated unit. In the study by Fels and Weiss (2001), the perception of the remote sick students' attitude toward the PEBBLES interactive videoconferencing system became more positive over time, although there appeared to be an increasing trend that is not significant for their health, individuality, and vitality. Watanabe $(2001,2007)$ and Watanabe et al. (2003) developed a speech-driven embodied communication system that consisted of a virtual system with InterActor and a physical system with InterRobot. The system was operated by speech of tele-operators that might be teachers or students.

\section{Robot Roles and Target Group}

With respect to the role of a robot, peer-tutor took the dominant form (e.g., Kanda et al., 2004; Han et al., 2005; Hyun et al., 2008; Movellan et al., 2009) followed by teaching assistant robots (e.g., Han \& Kim, 2006, 2009; You et al., 2006; Yujin, 2008) as shown in Fig 1. Study targets comprised pre-school children (e.g., Hyun et al., 2008; Movellan et al., 2009; Yujin, 2008), and elementary school children (Kanda et al., 2004; Han et al., 2005; Han \& Kim, 2006, 2008; You et al., 2006; Han et al., 2009a). Some robots, such as Papero, embraced a wide range of user targets, including pre-school children, adults, and even elders (Osada, 2005) taking the role of a younger partner, an assistant, an instructor, and an elder partner, respectively.
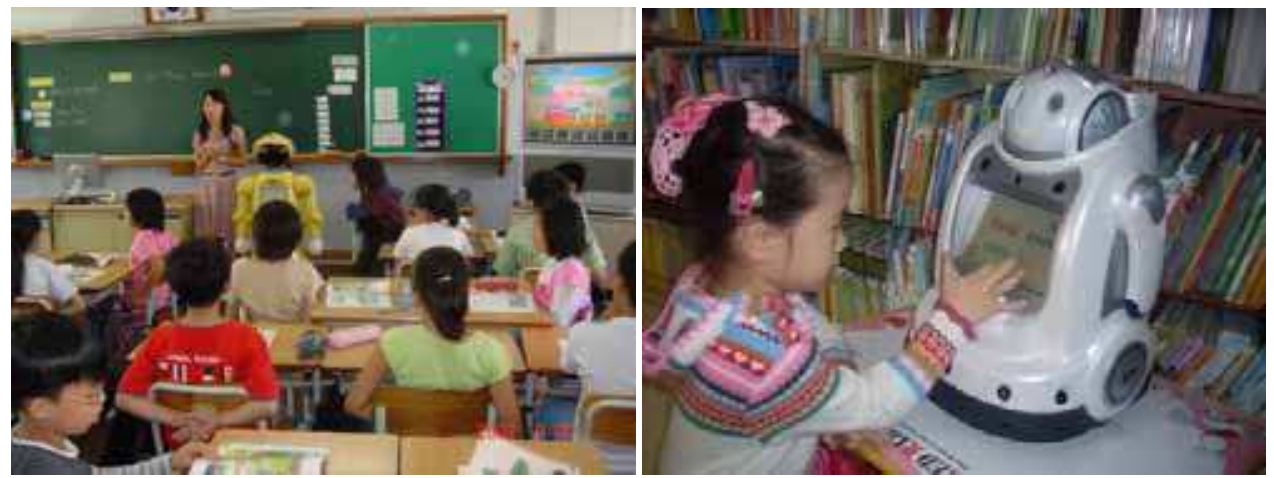

Fig. 1. Roles: Teaching Assistant Robot in English and Peer Tutoring Robot

\section{Subject Suitability}

Han and Kim (2006) performed a Focus Group Interview (FGI) study with 50 elementary school teachers who were relatively familiar with robots and information technology. The survey results showed that the classes that teach foreign language, native language, and music are suitable for r-Learning services. Most teachers used educational service robots for language courses, such as English class (Kanda et al., 2004; Han et al., 2005; Han \& Kim, 2006), native language class to acquire vocabulary (Hyun et al., 2008; Movellan, 2009), Finnish vocabulary (Tiffany Fox, 2008), and Chinese class (Yujin, 2008). However, robots also assisted other classes, including ethnic instrument lessons (Han and Kim, 2006), and 
music class (Han et al., 2009a). In addition, Yujin (2008) expanded the range of robot learning in various areas, such as teaching science, learning how to cook, and supervising homework.

\section{Visual Instruction}

The teaching interaction provided by these robots may or may not include teaching materials from a screen-based robot. A teaching assistant robot that uses screen-based material can share much of its educational frame with e-Learning (electronic-Learning). Indeed, the teaching interactions of robots often request screen-based teaching materials such as CAI or WBI. r-Learning services may often need screen-based materials. Educational service robots have provided instruction materials in the following literature: Han et al. (2005), Han and Kim (2006, 2008), Hyun et al. (2008), Han et al. (2009a, 2009b), Movellan et al. (2009), and Yujin (2008). Most of the instruction materials were created via Flash, which has often been used as an authorized tool for WBI. Thus, instructors can interact by displaying instruction materials based on e-Learning for robots that have a touch screen. The screen- based interaction has the advantage of being able to also be used as the replacement for failed voice or vision recognition, which makes this technology appropriate for r-Learning services.

\section{r-Learning Services}

Robovie in Kanda et al. (2004) offered voice-based casual English conversation, and nonverbal communication such as playing rock-paper-scissors. Also, Osada (2005) made Papero perform the following activities: conversation, different reactions for touching different points, roll-call of attendees, quizzes, communication over mobile phone, and making stories. Kanda et al. (2007) revealed that robots might need to use children's native language in order to establish relationships as well as to teach foreign languages. Robovie serves hundreds of interactive behaviours such as shaking hands, hugging, playing rock-paperscissors, exercising, greeting, kissing, singing, briefly conversing, and pointing to an object in the surroundings. Moreover, Robovie could call children's names by RFID tags and confide personal matters to the children who had interacted with it for an extended period of time. Those services made children interact with Robovie over the long-term.

The teaching assistant robots in Han and Kim (2009), and Han et al. (2009a) provided class management services, such as checking students' attendance, getting attention, being a time clock for activities, selecting random presenters, and instructing classes, such as giving quizzes. In these studies, RUBI, a fun-looking, and bandana-wearing robot tutor interacted with children to teach them numbers, colours, vocabulary and other basic concepts. RUBI sang popular songs and danced, while presenting a related video clip on the screen, and provided Flash-based educational games with its physical activities for improving toddler's vocabulary. You et al. (2006) from Taiwan utilized tablet PC and blue-tooth technology in order to deploy Robosapien as a teaching assistant. Robosapien had five models: storytelling model, Q\&A model, cheerleader model, let's act model, and pronunciation leading model. Robots with touch screens can provide augmented reality (AR), the overlaying of computer graphics onto the real worldview, as well as augmented virtuality (AV), the overlaying of real objects into the virtual space view, as presented in Milgram's virtual reality continuum (Milgram \& Kishino, 1994). Han and Kim (2006) identified that the service using robots' touch screens can positively stimulate children in class. In their study, they made the robot display children's photos to use them for checking attendance and selecting a presenter. 
Han et al. (2009b) suggested that there is a high potential for the commercialization of robots in educational settings, and expected that the AV service of robots to be a positive influence in opening the robot markets. Similarly, Movellan et al. (2009) offered an AV service that allowed clicking on children's faces. Hence, the relationship between robots and children may become more intimate and solid, one that will last for the long-term when in the future such AR service based screens become technically affordable. Yet, not all robot services utilize touch screens. Watanabe (2007) introduced the AR version of SAKURA, which activated group communication between a virtual teacher, InterActor, students, and InterRobot in the same classroom. This study forecasts that AR can enhance human-robot collaboration, particularly in learning and teaching because AR technology has many benefits that may help create a more ideal environment and communication channels such as an ego-centric view and ex-centric view mentioned by Green et al. (2008).

\section{Field Experiment}

Field experiments of educational service robots require the robots' stable operation, parental and school's consent, and a means to protect privacy. If the robot acts as an assistant, the study may need a lot of resources in terms of time and money, and the interaction capability of the instructor remains as a factor of non-sampling error. Also, a field study that involves a robot as an assistant may be largely influenced by the degree of technology acceptance of the main teacher. A theoretical basis for new technology spread, using the Innovation Diffusion Theory of Rogers (1995), can be found in the Technology Acceptance Model (TAM) proposed by Davis (1989). Davis (1989) attempted to explain an individual's actual behavior or behavioral intentions, based upon the user's perception of the usefulness and ease of use of a particular piece of Information Technology (IT). Furthermore, a study that involves children should be carefully devised to control the factor of non-sampling error in children's responses. Also, an existing theory on the adoption and distribution of a new technology can be applied to educational robots since their software design and manufacture are based upon IT. Therefore, in experiments where robots act as peer tutors, they interact with children for two weeks straight as in Kanda et al. (2004) or Movellan et al. (2009). In experiments using a robot as an assisant teacher, robots are either exposed for a longer period with four repetitive sessions per month, such as in Hyun et al. (2008), or robots interact with a larger group of participants in a single session with some pre-study activities to miminze novelty effect, as in Han et al. (2005).

Whether it lasts for a single session or for a month, all these studies have suggested meaningful results in movitation to learn language and in academic achievement. In general, studies have primarily assessed how effectively robots convey verbal communication, non-verbal communcation, such as gestures, and TPR and so forth. Han et al. (2005) reported that the RAL group showed the biggest achievement among the noncomputer-based learning group, web-based learning group, and RAL group. Also, Hyun et al. (2008) reiterated the improved linguistic ability of pre-teen children through a series of story making tests, vocabulary tests, story understanding tests, and word recognition tests. Movellan et al. (2009) investigated the effects on knowledge of target words taught by RUBI, which is fully autonomous and has a touch screen, to toddlers over a period of two weeks. They reported that there was a significant improvement in the learning of 10 words to the 9 toddlers (aged 15 through 23 months). Finally, Tomio (2007) and Yujin (2008) began commercializing educational assistant robots for toddlers. 


\section{3. r-Learning services}

\section{1 r-Learning services}

In general, r-Learning services can be currently defined as pedagogical and interactive activities which can be reciprocally conducted and interacted between learners and anthropomorphic educators, i.e. robots, in both the real and virtual worlds. There exist some significant differences between totally internet-based e-Learning and robot-based $r$ Learning. First, there is reciprocal authority to start learning. E-learning is passive and can only start when the learner logs in of his own accord. However, robots have the ability to suggest that the learner start, making r-Learning somewhat active. Second, there is more responsiveness of teaching and learning activities. General computers do not take action but instead let the learner's action happen to them, but robots based on autonomous recognition can be responsive to the learner. Third, there is greater frequency of physical and virtual space. E-Learning can only occur in the virtual world, but r-Learning can be conducted not only physically in the real world, such as in classroom, but also in the virtual world, such as through the touch screen of robots or on TV. Furthermore, unlike computers, robots can interact with learners by direct contact, i.e. warmly hugging learners. Fourth, the anthropomorphism of media for learning is better in robots. Robots can function as both learning media and anthropomorphic educators that can make relationships and interactions between learners and robots. On the other hand, computers used for e-learning are simply learning media. Moreover, robots are avatars themselves both in the real world and in the virtual world, whereas there is nothing for computers to do but to insert avatars into the virtual world. Fifth, robots can provide physical activities to reinforce learning. Learners can directly and physically contact robots by seeing and touching them, imitating them and moving with them. Robots are very suitable for TPR learning. So the learners' physical interaction with robots is much better than in e-Learning, where learners have to stay in front of a computer screen. Sixth, robots serve as a convenient means of communication between teachers and parents, one that may incidentally reinforce the relationship between children and their parents. Robots can take photos of the children engaged in classroom activities for the children's class portfolios, and then send the photos to parents via e-mail or mobile phone. Seventh, robots simplify providing fantasy for immersion learning. Robots can more automatically serve augmented virtuality via their camera, mobility and search functions as shown in Figure 7. Computers cannot compete at the same level. The service of augmented virtuality can help learners enhance both their motivation and immersion.

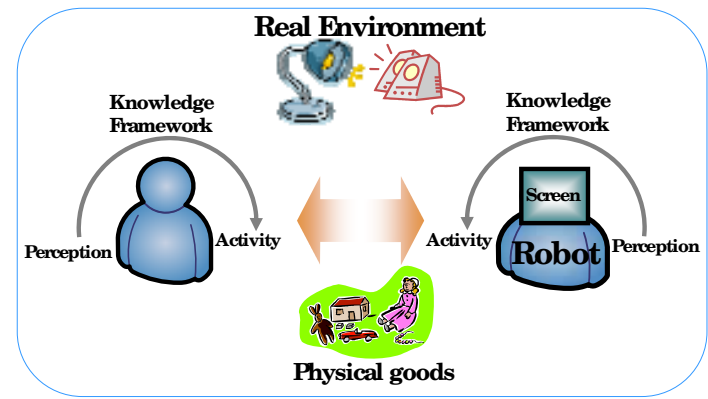

Fig. 2. r-Learning services: Interaction between Learner and Teaching Robot 
R-Learning services are based on the interactions between a teaching robot and learners. The interaction occurs through the knowledge framework of a teaching (or teaching assistant) robot after perceiving data from external sensors, as shown in Figure 2. The sensing data may be influenced by real environmental factors, such as light, sound, and obstacles. Educational service robots should possess some level of artificial intelligence, so that they are equipped to perceive physical events and take appropriate action based on the TPCK framework.

However, the knowledge framework of a teaching robot is still at an early stage due to the limitations of today's technology. For a tele-operated TA robot, the TPCK framework may be supported as shown in (a) of Figure 3 (the TPCK framework image is from the site http://www.tpck.org/). Moreover, the autonomous robots are a long way from the teacher's framework of TPCK. That is, the r-Learning services of autonomous robots would be in the teaching assistant framework of TCK along with pedagogical knowledge from the teacher. Autonomous robots have TCK that autonomously shares content via touch screen and TV with children but present robots have technological limitations by not being equipped with TPCK, as shown in (b) of Figure 3.

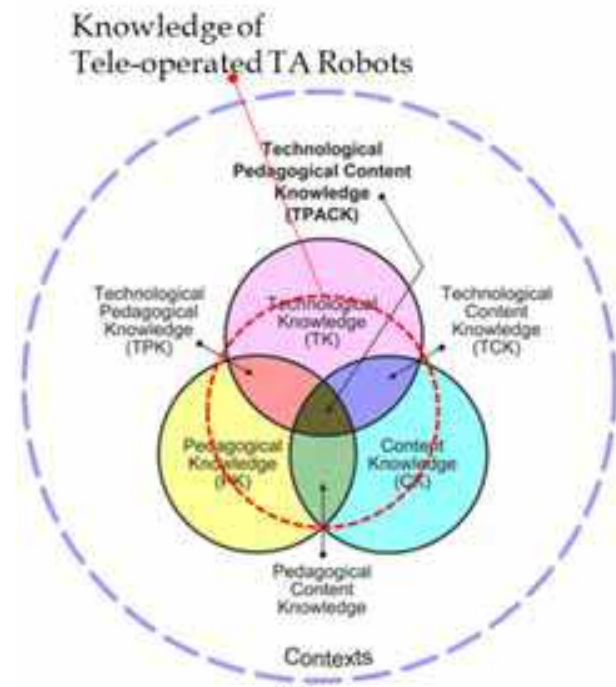

(a)

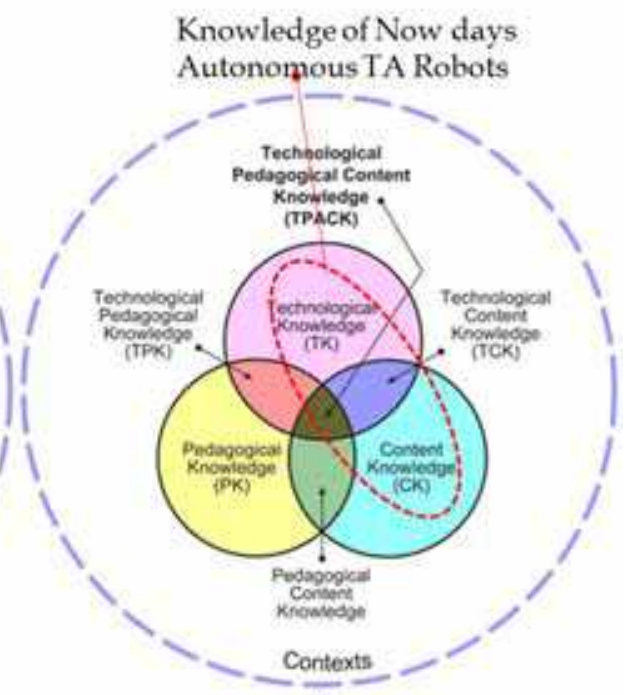

(b)

Fig. 3. Teaching Assistant Robot in TPCK framework

R-Learning services include learning activities that utilize a direct physical experience, such as chanting and dancing (Kanda et al., 2004; Han et al., 2009a; Yujin, 2008), and learning that uses teaching props such as toys (Yujin, 2008; Movellan et al., 2009), and that delivers multimedia contents through a touch screen (Han et al., 2005; Han and Kim, 2006; Hyun et al., 2008). This final type of activity for delivery of multi-media contents can sub-divided into two categories: class management and class instruction (Han et al., 2009a). Class instruction can further be sub-divided into contents delivery type (Han et al. 2005; Han and Kim, 2006; Hyun et al., 2008) and participatory type through augmented virtuality (Han et al., 2009b), depending on the participation of the learners. 


\subsection{Services framework}

A service is a non-material product that is well consumed and utilized by the requesting consumer to support his need. Webservice is a software system designed to support interoperable machine-to-machine interaction over a network defined by the W3C. Robot service consists of a collection of interactions between human and robot in authentic environments. Robot service is similar to a pure and pure commodity goods service. Although some utilities actually deliver physical goods, utilities are usually treated as services. For example, robots bring a physical good (a cup of water and medicine to elders when in need), but also provide services (calling their attention to their health). Similarly, rLearning services refer to the interactions that robots provide for educational purposes. To date, most of the reviews of literature from previous studies in this field have not mentioned the framework of r-Learning services. In this study I have constructed an r-Learning services framework for autonomous robots based on web-based services because $r$-Learning services have stemmed from e-Learning services. The framework of tele-operated robot services is similar to that of videoconferencing, and consists of tele-operated robots and the supporting system to control their multi-modal interface via the Internet.

Web services refer to those that provide a variety of services to users by inter-connecting devices and applications through networks. Web service is required for users to access the system through any device. A web-based e-Learning system interacts with an operational environment, called the Learning Management System (LMS), through SCORM (Sharable Content Object Reference Model) standards, which are a collection of standards and specifications for web-based e-Learning. These define communications between the client side content and a host system, called the run-time environment (commonly a function of the learning management system). LMS is a system that plans, communicates and manages educational materials in on-line and virtual classrooms both. LCMS, however, is a multiuser system that can produce, store, recycle, and manage digital learning materials, and transfer them to users. The following figure suggests a framework for e-Learning and $\mathrm{r}$ Learning services.

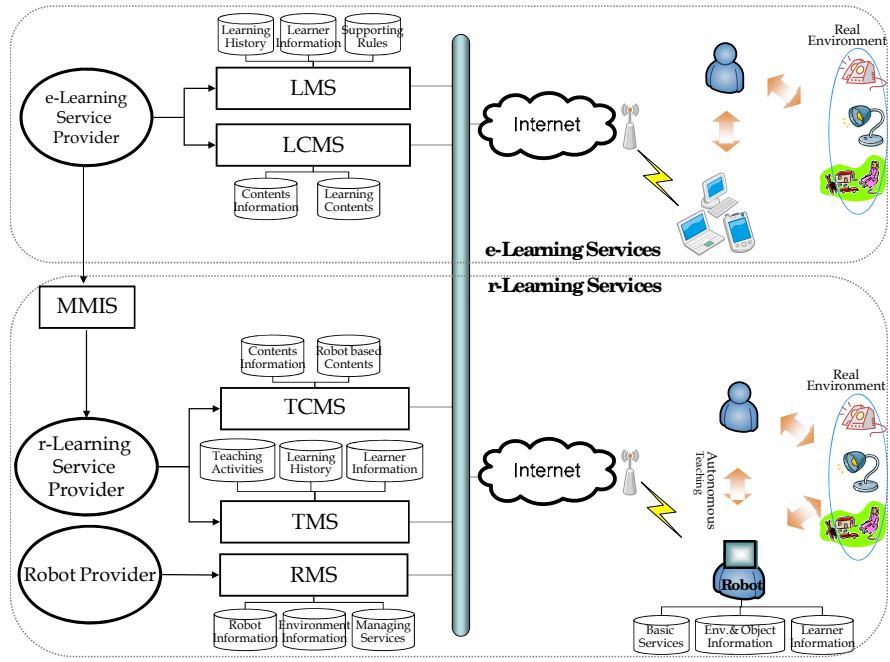

Fig. 4. Service Framework for Teaching Robots 
In the e-Learning service framework, users learn educational materials provided by LCMS and LMS in their personal devices, such as a computer, and a PDA. In this case, learners only initiate the interaction because the devices do not have sensors. In the r-Learning service framework, the Teaching Content Management System (TCMS) is necessary for managing robot-based contents. The contents in TCMS differ from those in LCMS because robot-based learning requires emotional interaction that has expression and action. Therefore, in order for LCMS contents to transfer to robot-based multi-modal contents, it needs MMI (Multi Modal Interface). In the same way, e-Learning service providers should convert e-Learning contents into robot-based contents through MMIS. Teaching robots should download appropriate robot-based contents and utilize them autonomously. To this end, the robot service provider should support TMS (Teaching Management System), which allows robots to interact with TCSM on the network and be able to instruct. TMS not only manages teaching based on learner information and learning history, but also contains various teaching activities. The r-Learning service framework should have an RMS (Robot Management System) that can manage robots on the network. Namely, a robot provider can even manage information (e.g. model number and software version) on schools that bought robots, on the physical environment in which it operates, and on the service record. Also, it may have information on its hardware capability, information on the user (school or teacher), information on some objects (e.g. text books, teaching props) and environment (e.g. number of classrooms, position of robots among classrooms) and essential knowledge to support the basic service when it is off the network.

\subsection{Design of r-Learning services}

This section discusses the factors that need to be considered when designing r-Learning services. There is an example of dynamic services of a teaching assistant robot in Figure 5.

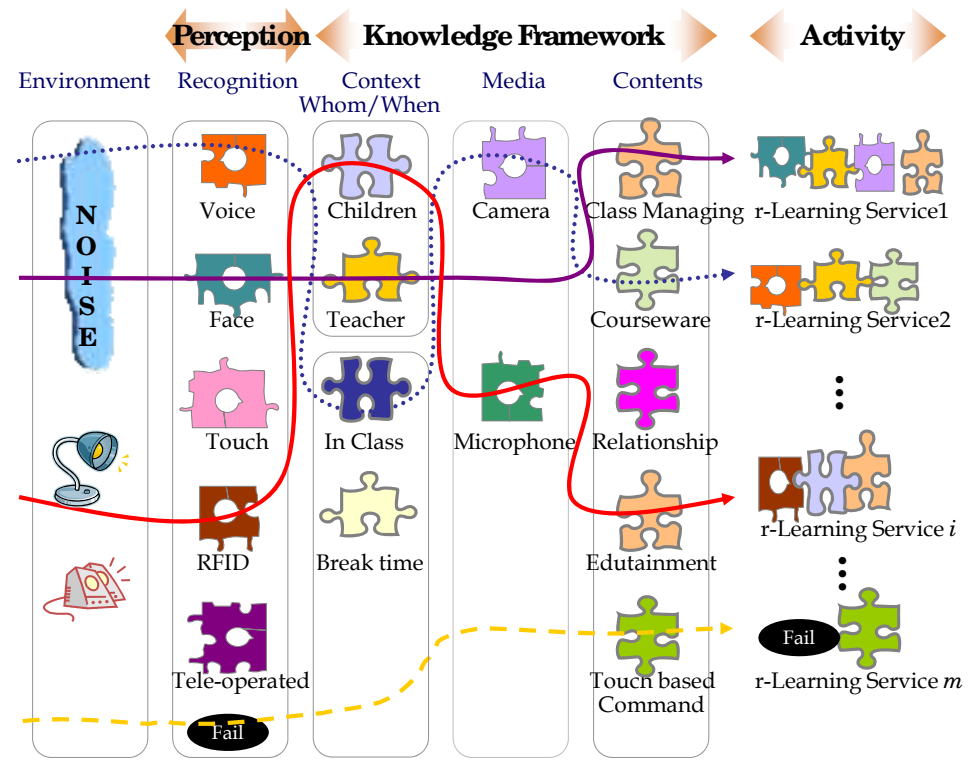

Fig. 5. Examples of Constructing Dynamic r-Learning Services of Teaching Assistant Robots 
The first $r$-Learning service operates the command of class management from an instructor through a facial recognition system. The second r-Learning service provides an augmented virtuality service using a camera that operates on voice commands given in the class. The $i^{\text {th }}$ r-Leaning service is an educational game, or edutainment, that a child plays after he or she has been recognized through a RFID tag. The $m^{\text {th }}$ r-Learning service uses the touch screen for command because of failed-voice recognition.

This study explains the design requirements of the three types of services (physical activities, teaching props, multimedia contents based touch screen) discussed in Section 3.1. For r-Learning services that utilize physical activities, such as TPR, it is important to make children practice with their own bodies. For r-Learning services that utilize teaching props, such as books or balls, the design is required to include tactile sensing and object recognition. For the r-Leaning services that use multi-media contents, the design needs to support tools, such as Flash, and should utilize both vision and voice recognition to understand a learner's progress. Consequently, this type of service requires a multi-modal script design consisting of TTS and expressions modelled based on pedagogical knowledge, such as educational psychology. Furthermore, it requires a high quality augmented virtuality service, which will enhance the motivation of children in class.

The process of design for r-Learning services is as follows: (1) analysis of the technical capacity of vision, voice, emotion, non-verbal, and object recognition to maximize the autonomy of the robot hardware and software; (2) planning of a knowledge framework for the robot within given technical specifications; (3) developing the teaching scenario, which consists of a series of robot actions and Flash-based (in most of the cases) visual materials for the touch screen, created based on the knowledge framework; (4) GUI design for the visual material in the scenario occurs; (5) final assessment to confirm whether the teaching scenario has maximized the autonomy of the robot hardware, including anthropomorphism, and to consider the collaborative efforts with the teachers; (6) design reiteration begins after this evaluation.

\section{Case study on r-Learning services of teaching assistant robots}

This chapter discusses case studies relating to r-Learning services using an assistive robot. Two field studies were conducted: one in an elementary school and the other in a kindergarten. The r-Leaning services in each arena aimed to provide class management and learning materials, respectively. Also, the study explains the insights from children and instructors with more detail in the following sections.

\subsection{In elementary schools}

The teaching assistant robot, Tiro can help teachers as an educational media in class, and a classmate of the children for English learning. This study tried to reflect the concept of a human-friendly Internet-connected robot with e-Learning technology. The study developed the educational materials of 'How many cows?' for a 40 minute English class for 3rd grade students. Robot-based contents were uploaded to the TCMS server for public sharing by robot service providers. The instructor taught with a blackboard and a TV connected to a computer in the classroom. The classroom layout in the field work is displayed in Figure 6. Tiro could be downloaded from the TCMS server by the teacher's voice command through wireless internet, and then transferred to projection TV. A classroom is a noisy environment 
that can influence the recognition rate for voice and vision. If recognition failed, teachers converted to the touch screen-based interaction. Teachers could also use a remote-control to interact with the robot if they were across the classroom. Tiro displayed and explained the learning material while the teacher roamed around the classroom and attended to any individuals who needed extra help.
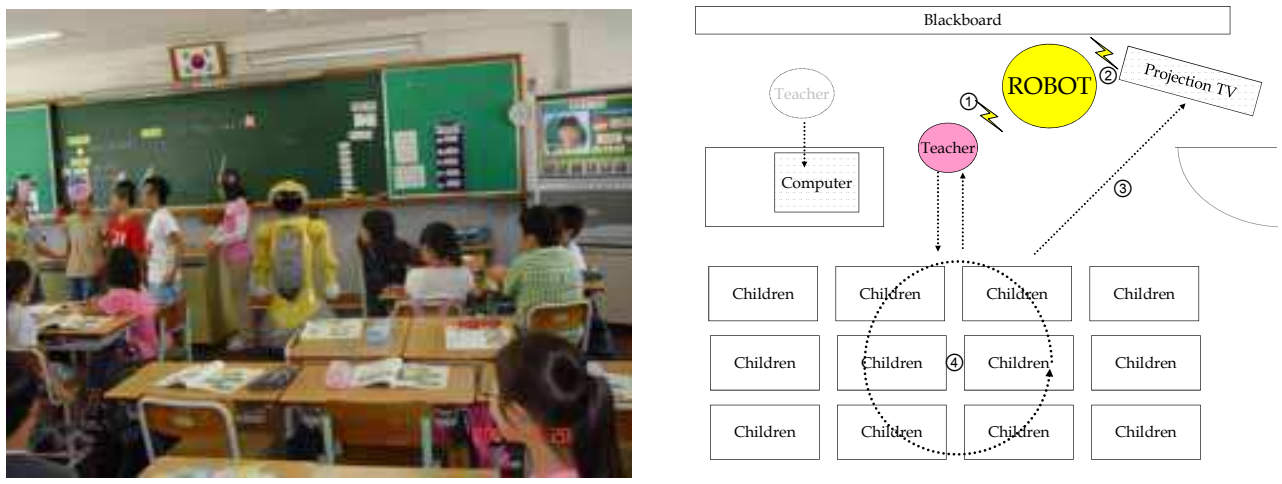

Fig. 6. Scene of Role Playing and Experiment in Classroom

Tiro's services contained multimedia objects such as the Flash files (SWF format), children's photos and names. Tiro's services were divided into two categories: (1) class management, such as checking students' attendance, getting attention, acting as a timer for activities, and selecting presenters; (2) learning materials transmitted to TV, such as providing lesson objectives, conversation scripts, English chants and dancing, storytelling and role playing, praising and cheering up, providing reviews and quiz games, and more. This study matched these types of services with the models suggested by You et al. (2006) as illustrated in Table 3.

\begin{tabular}{|c|c|c|}
\hline Services in classroom & $\begin{array}{l}\text { Han et al. (2006, 2009a, 2009b), } \\
\text { Han and Kim (2009), Yujin (2008) }\end{array}$ & You et al. (2006) \\
\hline Class Management & $\begin{array}{l}\text { Calling the roll } \\
\text { Concentration } \\
\text { Timer for activity } \\
\text { Selection of presenters } \\
\text { Checking homework } \\
\text { Recording the history of rewards }\end{array}$ & \\
\hline Language Learning & $\begin{array}{l}\text { Storytelling and role play } \\
\text { English chant and dance } \\
\text { Augmented reality role playing } \\
\text { Quiz for checking pronunciation } \\
\text { Quiz } \\
\text { Cheering up or praising after the quiz }\end{array}$ & $\begin{array}{l}\text { Storytelling/let's act model } \\
\text { Let's act model } \\
\text { Pronunciation leading } \\
\text { model } \\
\text { Q\&A model } \\
\text { Cheerleader model }\end{array}$ \\
\hline
\end{tabular}

Table 3. Comparison with You et al. (2006)'s model for a teaching assistant robot 
The following Figure 7 illustrates Tiro's teaching services. In the first column, calling the roll shows the situation where the robot calls children's names to check their attendance. The next column, augmented reality role playing shows how the robot provides a role playing service by graphically treating children's pictures to become animation characters in order to increase motivation for learning, as suggested by Han et al. (2009b). The third column, conversation and role play, describes how the robot and children play a game together as a team.

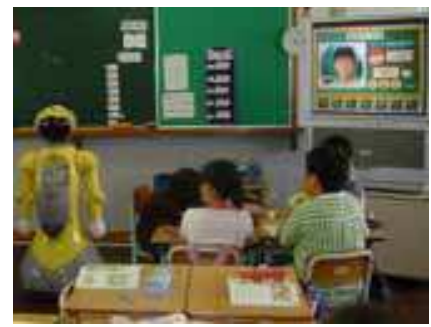

Calling the Roll

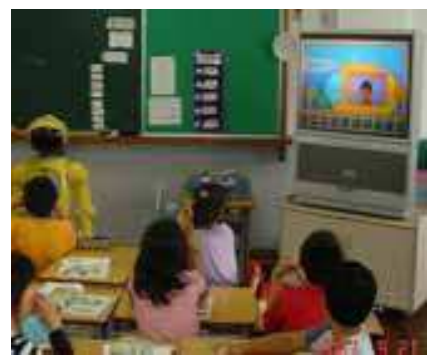

Selecting Children to Present Augmented Reality Role Playing

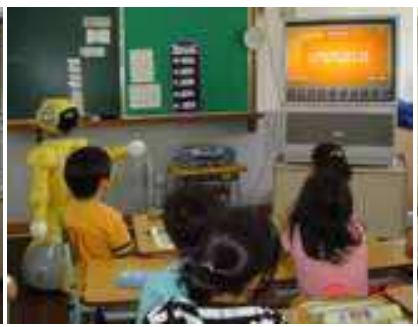

Getting Attention

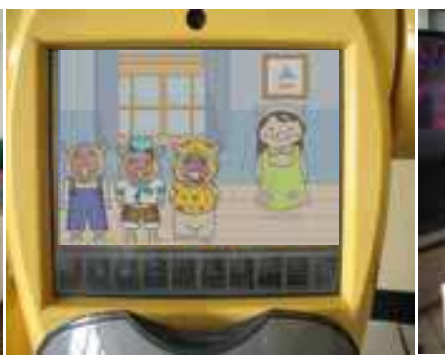

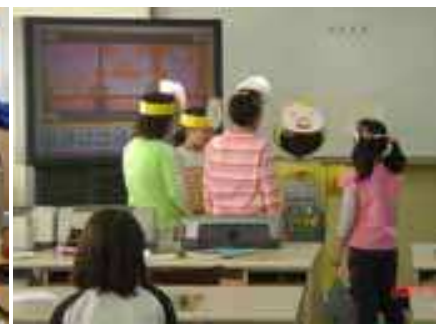

Conversation and Role Play

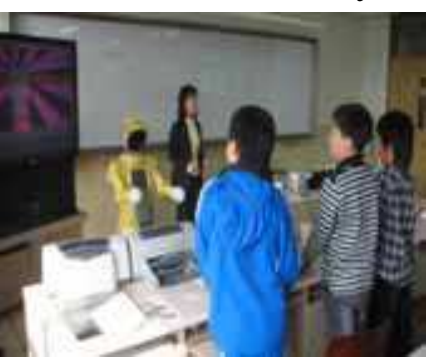

English Chant and Dance

Fig. 7. Some of Tiro Services as Teaching Assistant

Experiments were executed in three English classes in a Korean elementary school. Each class lasted for 40 minutes. In total, 117 children participated in the classes while 20 teachers monitored the classes. To investigate children's responses, the study randomly selected 27 out of the 117 children, and then surveyed them. The study asked questions such as 'Which do you prefer among Tiro's services?', and the children could choose plural preferences. Figure 8 displays the four favourite services that came out of the study, and categorizes them according to who used the service and how much they cooperated. The services preferred by children are illustrated in a yellow circle, those preferred by teachers are represented in blue hexagons and those preferred by both groups are represented in a green rectangular. In general, children liked services that were centred around them, while teachers preferred those that focused on them. Attendance checking was one exception. It was guessed that children preferred it because of the novelty effect of robots recognizing each individual. Teachers spoke of it less desirably because robots had difficulties in 
recognizing children's voices and faces in the noisy and busy classroom environment, which made this activity more time-consuming than before.

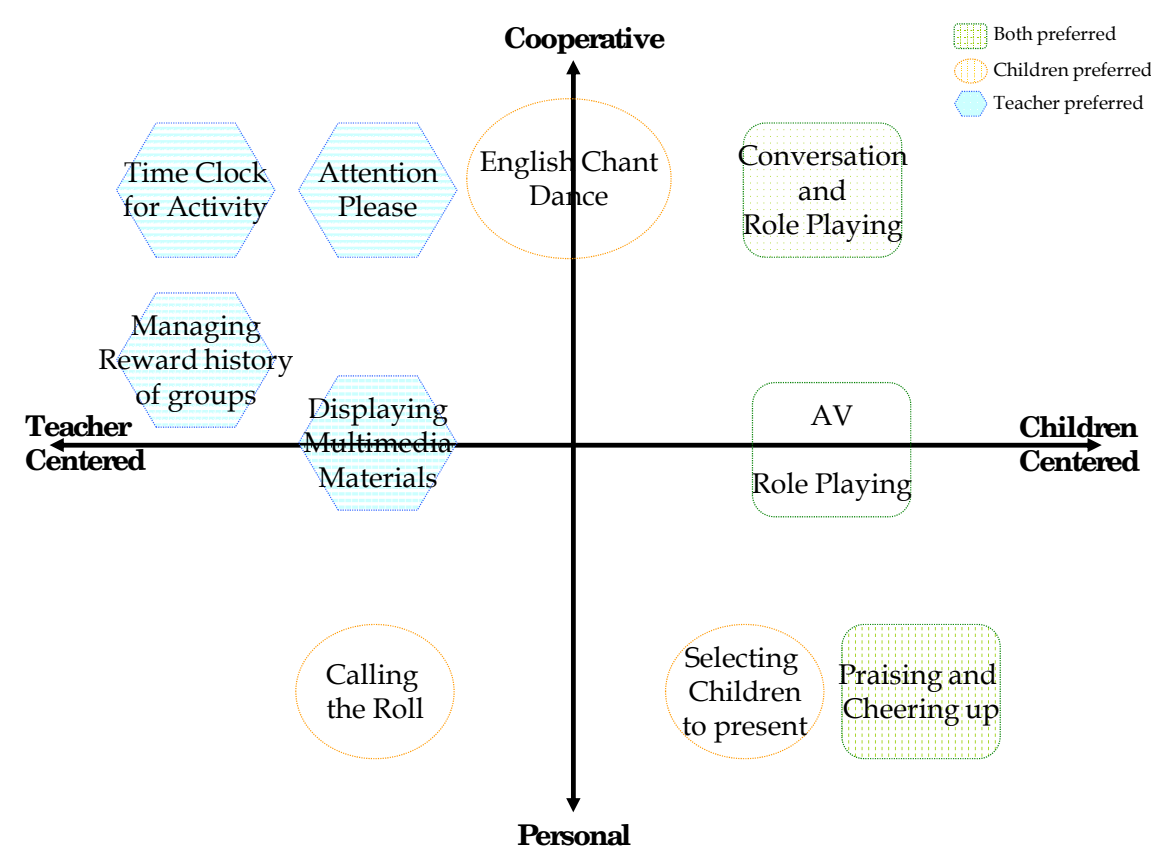

Fig. 8. Popularity of Tiro's Services in English Class

The most popular service was Tiro's praising and cheering up, which enhanced the relationship between children and Tiro in English class. The second one was face-to-face conversation and role play with Tiro. Particularly, the skits using identification based augmented virtuality appear to have had effects on children's motivation for learning. Next in rank was English chant and dance. Calling the roll and selecting a child to present ranked similarly, but the former carried a bigger impact because all children could interact with Tiro. For the teacher group, teachers preferred Tiro's accommodating services rather than those that enhanced the relationship between children and Tiro. The results also showed that teachers preferred face-to-face conversation and role play with Tiro because the robot could pronounce English words better than them. Tiro's praising and cheering up service and display of multimedia presentations were ranked next. Through Tiro's assistance, teachers expected to have more time to interact with and help students individually by reducing the amount of time they spent at the front of the classroom to change slides on the computer. The teachers' expectation on the learning effect with Tiro was positive, with an average value of 3.6 ( $\mathrm{p}$-value=0.0001) on a five-point-scale. In follow-up interviews, the teachers also recommended that the encyclopaedia services of Tiro be used during break 
time and that Tiro could take photos of classroom activities and automatically upload these photos to the school web server for viewing by parents.

\subsection{In kindergartens}

Up to now, Yujin robotics has begun r-Learning services using iRobiQ in about a hundred kindergartens (Yujin, 2008). The following figure (Figure 9) shows an example of a TMS server. This system comprises a set of menus, such as an introduction for this r-Learning service and iRobiQ, uploading and downloading of r-Learning contents, classroom management for teachers, and general information for parents.

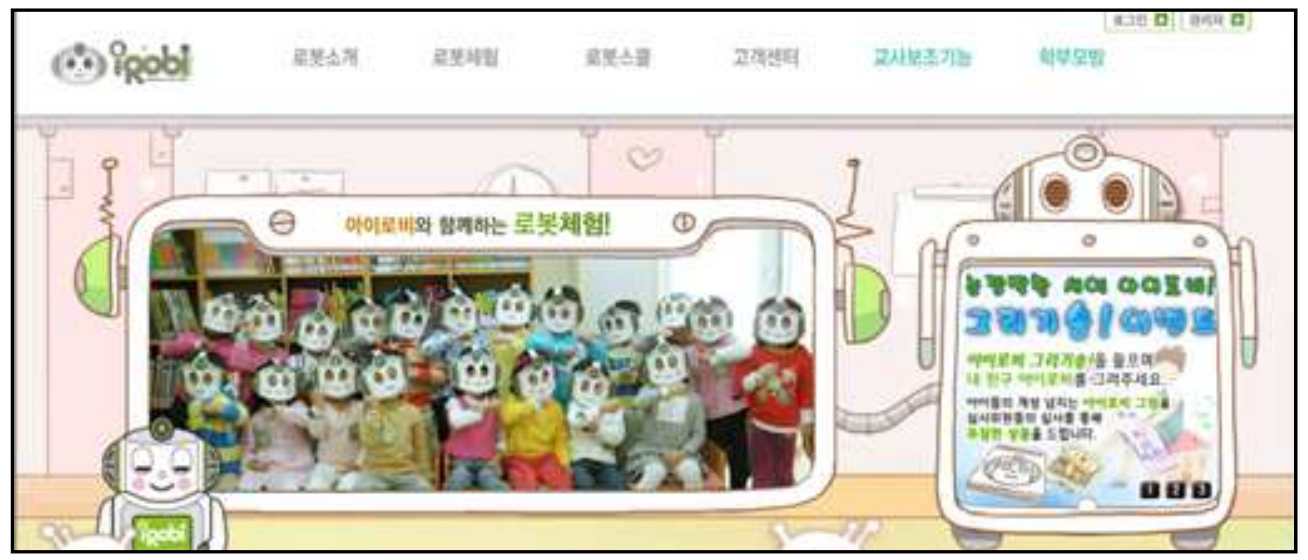

Fig. 9. An Example of TMS Server (http://www.edurobot.net/)

Under teachers' supervision, iRobiQ performs such activities as checking attendance, supporting English learning, reading books, playing music, guiding and arranging daily activities (e.g., making beds, eating, and cleaning), compiling academic portfolios, and then transferring them to parents. If iRobiQ fails to recognize children's faces when checking attendance, it provides a photo menu for children themselves to enter the information. The following Figure 10 illustrates a situation in which iRobiQ dances with children in a TPR dance class. To instruct daily activities, teachers let iRobiQ inspect the cleaning, sing a lullaby during naptime, and teach general eating etiquette, such as standing a line in a cafeteria, washing hands before eating, and more. Also, iRobiQ takes photos of the children engaged in classroom activities for the children's class portfolios, and then send the photos to parents via e-mail or mobile phone. The compiled portfolios are historically valuable to both children and parents, and allow the parents to understand and follow the kindergarten life of their children more closely.

A teacher said that "Although iRobiQ does not walk on two feet like a humanoid and delivers a cup of water, it supports linguistic development by interacting with children as an assistant teacher and instructs everyday knowledge by how to behave in daily life. 
Furthermore, it is very important that iRobiQ can share emotional experiences with children as their friend. Most importantly, $\mathrm{iRobiQ}$ frees up more time for the teachers to give extra attention to students because it shares our workload." Another teacher commented that children who are the only child tend to think of iRobiQ as a younger sibling and try to become a role model for it. A growing number of studies with similar topics have been conducted, and the results will soon be available through publications. Also, the teacher added that vicarious reinforcement occurred at the beginning as children mimicked the robot and sang and danced in the rigid form that iRobiQ demonstrated. However, the teacher assured that it happened out of curiosity, and faded away soon after.
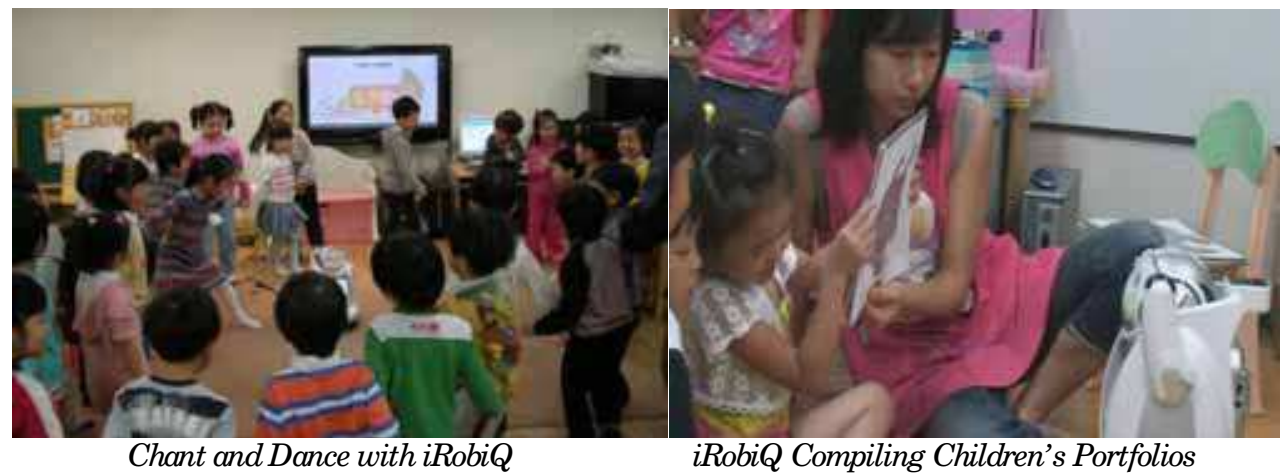

iRobiQ Compiling Children's Portfolios

Fig. 10. iRobiQ's Services as Teaching Assistant

\section{Conclusion and discussion}

Very recently, many researchers have shown much more interest in the pedagogical effects of educational service robots. Depending on the location of the knowledge framework of educational service robots, the robots are categorized into three types: autonomous, teleoperated, and convertible. Most of the current educational service robots inter-connect their knowledge framework with a web service. These types of robotic services are referred to as r-Learning, or robot-aided learning.

In this study, r-Learning services are defined as the interaction between a learner and a robot that occurs for educational purposes. To date, the knowledge framework of educational service robots primarily consists of technology and subject contents with almost no pedagogical knowledge, making the teacher's pedagogical knowledge still important. Therefore, referring to it as r-Learning instead of R-Learning may be more appropriate until the day when there is unity between artificial intelligence and human intelligence, as forecast by Kurzweil (2005).

Also, this study reviewed previous studies relating to r-Learning, and categorized them into r-Learning services according to the types of robots, their role, and so on. A literature review revealed that most of the existing r-Learning services utilize web-based contents as the information that robots provide. Many of them confirm that the use of robots can positively contribute to improving learners' motivation for learning, which has led to the commercialization of a teaching assistant robot. 
This study concludes r-Learning has the seven advantages: reciprocal authority to start learning, responsiveness of teaching and learning activities, greater frequency of physical and virtual space, the anthropomorphism of media for learning, providing physical activities, convenient communication for teachers and parents, providing fantasy for immersion learning. It was proposed r-Learning service frameworks based on the frameworks of web-based services and teacher's knowledge. Also, this study defined rLearning services as a set of activities in the knowledge frameworks built around the perceived sensor data, and divided the activities of r-Learning services into three types: physical experience type, using teaching prop type, and multimedia content based on screen type.

The design of r-Learning services are made up of five steps: the design of vision, voice, emotion, non-verbal, and object recognition; the construction of robots' knowledge framework within a given technical circumstance; the creation of a robot education scenario within the boundary of the knowledge framework of robots, in which the scenario normally includes robot actions and visual materials (normally Flash-based) for the touch screen; the design of GUI for the visual material in the scenario; and confirming whether the teaching scenario maximized the autonomy of the robot hardware, included anthropomorphism, and considering the collaborative efforts with the teachers. Design reiteration begins after this evaluation.

Case studies conducted on r-Learning services development in an elementary school and a kindergarten were introduced. By observing how students and teachers interacted with rLearning services, the study found an r-Learning paradigm based on its educational impact and emotional communication in the upcoming future.

However, challenges remain. The challenges for tele-presence robots include ethical violations that may come from the field. These robots may invade privacy by intruding into personal school lives of students. Other challenges include protecting the system from misuse outside of a class led by a tele-presence system with a remote instructor, such as information leaks on the classroom itself, unapproved visual and audio recordings, and distribution of such recordings. Next, in the case of an autonomous robot, the recognition technology and the knowledge framework of a teaching robot are still limited. Robot expressions are minimized to meet the minimal hardware specifications required for commercialization. Recognition often fails in a real environment. The cost benefit and uniqueness have been controversial in comparison with computer based content services that also utilize camera and recognition techniques. A high level of TPCK is required for teachers to constantly interact with robots.

Finally, among TPCK, the PK that can elicit a long-term interaction beyond the novelty effect needs to be studied in depth. Several possibilities exist to overcome these challenges including the improvement of a recognition technology, such as using RFID, the development of a new interaction service between the physical activity type and teaching prop type, the development a means to increase the relationship with a robot, continuous studies on an acceptance model of teachers to use a teaching assistant robot.

\section{Acknowledgment}

This work is supported by Korea Evaluation Institute of Industrial Technology Grant \# KEIT-2009-S-032-01. 


\section{References}

Goodrich, M.A. and Schultz, A.C. (2007). Human-robot interaction: a survey. Foundations and Trends in Human-Computer Interaction, 1(3), pp. 203-275.

Davis, F. D. (1989). Perceived usefulness, perceived ease of use, and user acceptance of information technology, MIS Quarterly, 13(3), pp. 319-340.

Deborah I. Fels, Patrice Weiss. (2001). Video-mediated communication in the classroom to support sick children: a case study, International eburnal of Industrial Ergonomics, 28, pp.251-263

Eunja Hyun, Soyeon Kim, Siekyung Jang, Sungju Park. (2008). Comparative study of effects of language education program using intelligence robot and multimedia on linguistic ability of young children, Proceedings of the 14th IEEE International Workshop on Robot and Human Interactive Communication (RO-MAN 2008), pp.187912, Munich, Germany

HeadThere Inc. (2009). Retreived from the web site, http://www.headthere.com/

James Hendler. (2000). Robots for the rest of us: designing systems "out of the box", Robots for Kids: Exploring new technologies for learning, ISBN:1-55860-597-5, pp. 2-7, The Morgan Kaufmann Publishers

Javier R. Movellan, Micah Eckhardt, Marjo Virnes, Angelica Rodriguez. (2009). Sociable robot improves toddler vocabulary skills, Proceedings of the $4^{\text {th }}$ ACM IIEEE Human Robot Interaction, ISBN:978-1-60558-404-1, pp. 307-308, March 11-13, La Jolla, California, USA

Jeonghye Han, Dongho Kim. (2006). Field trial on robots as teaching assistants and peer tutors for children, Proceedings of the Asia Pacific International Symposium on Information Technology, pp. 497-501, January 9-10, Hanzhou, China

Jeonghye Han, Dongho Kim. (2009). r-Learning services for elementary school students with a teaching assistant robot, Proceedings of the $4^{\text {th }}$ ACM IIEEE Human Robot Interaction, ISBN:978-1-60558-404-1, pp. 255-256, March 11-13, La Jolla, California, USA

Jeonghye Han, Dongho Kim, Jongwon Kim. (2009a). Physical learning activities with a teaching assistant robot in elementary school music class, Proceedings of the $5^{\text {th }}$ IEEE International bint Conference on Network Computing, Advanced Information Management and Service, Digital Contents and Multimedia Technology and its Application (NCM 2009), pp. , August 25-27, Seoul, Korea

Jeonghye Han, Eunja Hyun, Miryang Kim, Hyekyung Cho, Takayuki Kanda, Tatsuya Nomura. (2009b). The cross-cultural acceptance of tutoring robots with augmented reality services, International eburnal of Digital Content Technology and its Applications, IBSN:1975-9339, pp.95-102

Jeonghye Han, Miheon Jo, Sungju Park, Sungho Kim. (2005). The educational use of home robots for children. Proceedings of the 14th IEEE International Workshop on Robot and Human Interactive Communication (RO-MAN 2005), pp. 378-383, August 13-15, Nashville, TN, USA

Jim Van Meggelen. (2005). The problem with video conferencing, Retrieved from the web site 
http://www.oreillynet.com/etel/blog/2005/04/the_problem_with_video_confere .html

Junichi Osada. (2005). Scenario design for children care robot, Papero. Proceedings of Robot Design Forum, pp.29-36, November 4, Daejeon, Korea

Laurel A. Williams, Deborah I. Fels, Graham Smith, Jutta Treviranus, Roy Eagleson. (1997). Using PEBBLES to facilitate remote communication and learning, Proceedings of the $41^{\text {st }}$ Annual Meeting of Human Factors and Ergonomics Society, Communications, 5, pp. 320-324

Milgram, P. and F. Kishino. (1994). Taxonomy of mixed reality visual displays, IEICE Transactions on Information and Systems, E77-D(12), pp.1321-1329.

Punya Mishra, Matthew J. Koehler. (2006). Technological pedagogical content knowledge: a framework for teacher knowledge, Teachers College Record, 108(6), pp. 1017-1054.

Ray Kurzweil. (2005). The singularity is near: when humans transcend biology, ISBN:0670033847, Viking adult press.

Rogers, E. M. (1995). Diffusion of Innovation, New York, The Free Press.

Scott A. Green, Mark Billinghurts, XiaoQi Chen, J. Geoffrey Chase. (2008). Humanrobot collaboration: a literature review and augmented reality approach in design, International eburnal of Advanced Robotics Systems, ISSN: 1729-8806, 5(1), pp.1-18.

Shulman, L.S. (1987). Knowledge and teaching: foundations of the new reform, Haward Educational Review, 57(1), pp.1-22.

Takayuki Kanda, Rumi Sato, Naoki Saiwaki and Hiroshi Ishiguro (2007). A two-month field trial in an elementary school for long-term human-robot interaction, IEEE Transactions on Robotics (Special Issue on Human-Robot Interaction), 23(5), pp. 962-971.

Takayuki Kanda, Takayuki Hirano, Daniel Eaton, Hiroshi Ishiguro. (2004). Interactive robots as social partners and peer tutors for children: a field trial, Human-Computer Interaction, 19(1\&2), pp. 61-84

Taylor, R. P. (Ed.). (1980). The computer in the school: Tutor, tool, tutee, New York: Teacher's College Press.

Telebotics Inc. http://www.telebotics.com/

Tiffany Fox. (2008). Meet RUBI the robot tutor, July 30, University of California News.

Tomio Watanabe. (2001). E-COSMIC: Embodied Communication System for Mind Connection, Usability Evaluation and Interface Design, 1, pp. 253 257.

Tomio Waranabe. (2007). Human-entrained embodied interaction and communication technology for advanced media society, Proceedings of the 16th IEEE International Conference on Robot \& Human Interactive Communication, pp.31 p36, Aug, 2007.

Tomio Watanabe, Masahi Okubo, Ryusei Danbara. (2003). InterActor for human interaction and communication support, Human Computer Interaction, pp.113 120, M. Rauterberg et al.(Eds.), IOS Press.

Yujin Robotics Inc. (2008). Ubiquitous home robot IROBI: Teacher Guide, white paper retrieved in 2008 . 
Zhenjia You, Chiyuh Shen, Chihwei Chang, Bawjhiune Liu, Gwodong Chen. (2006). A robot as a teaching assistant in an English class, Proceedings of the $6^{\text {th }}$ IEEE International Conference on Advanced Learning Technologies (ICALT'06), pp.87-91, July 5-7, Kerkrade, The Netherlands 


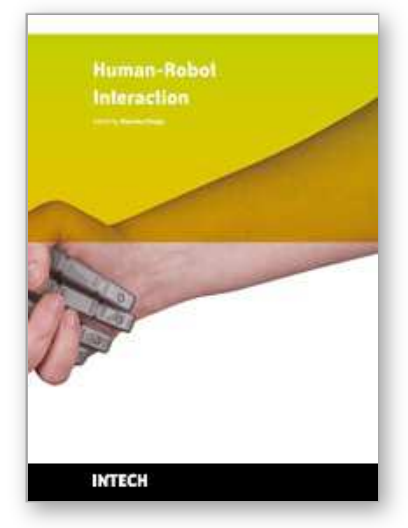

\author{
Human-Robot Interaction \\ Edited by Daisuke Chugo
}

ISBN 978-953-307-051-3

Hard cover, 288 pages

Publisher InTech

Published online 01, February, 2010

Published in print edition February, 2010

Human-robot interaction ( $\mathrm{HRI}$ ) is the study of interactions between people (users) and robots. $\mathrm{HRI}$ is multidisciplinary with contributions from the fields of human-computer interaction, artificial intelligence, robotics, speech recognition, and social sciences (psychology, cognitive science, anthropology, and human factors). There has been a great deal of work done in the area of human-robot interaction to understand how a human interacts with a computer. However, there has been very little work done in understanding how people interact with robots. For robots becoming our friends, these studies will be required more and more.

\title{
How to reference
}

In order to correctly reference this scholarly work, feel free to copy and paste the following:

Jeonghye Han (2010). Robot-Aided Learning and r-Learning Services, Human-Robot Interaction, Daisuke Chugo (Ed.), ISBN: 978-953-307-051-3, InTech, Available from: http://www.intechopen.com/books/humanrobot-interaction/robot-aided-learning-and-r-learning-services

\section{INTECH}

open science | open minds

\author{
InTech Europe \\ University Campus STeP Ri \\ Slavka Krautzeka 83/A \\ 51000 Rijeka, Croatia \\ Phone: +385 (51) 770447 \\ Fax: +385 (51) 686166 \\ www.intechopen.com
}

\author{
InTech China \\ Unit 405, Office Block, Hotel Equatorial Shanghai \\ No.65, Yan An Road (West), Shanghai, 200040, China \\ 中国上海市延安西路65号上海国际贵都大饭店办公楼 405 单元 \\ Phone: +86-21-62489820 \\ Fax: $+86-21-62489821$
}


(C) 2010 The Author(s). Licensee IntechOpen. This chapter is distributed under the terms of the Creative Commons Attribution-NonCommercialShareAlike-3.0 License, which permits use, distribution and reproduction for non-commercial purposes, provided the original is properly cited and derivative works building on this content are distributed under the same license. 